\title{
Coping with chronic pain in gastroenterology patients
}

\author{
Roman Jovey $\mathrm{MD}^{1}$, Paul C Adams $\mathrm{MD}^{2}$, Editor-in-Chief
}

$\mathrm{D}^{\mathrm{r}}$ Roman Jovey, a graduate of the University of Toronto (Toronto, Ontario), was a general practitioner and emergency physician for almost 20 years. In 1999, he closed his family practice to focus on his evolving interest in chronic pain management and addiction medicine. He has been involved in pain management for 15 years and addiction medicine for the past 25 years.

$\mathrm{He}$ is currently the Program Director at CPM Health Centres Inc (Mississauga, Ontario), a group of outpatient chronic pain management clinics, as well as the Physician Director of the Credit Valley Hospital's Addictions and Concurrent Disorders Centre (Mississauga, Ontario). He is the current President of the Canadian Pain Society.

PA: A very difficult problem for a gastroenterologist is the long-term management of patients with chronic pain. Two of the most difficult categories of patients are those with Crohn's disease and those with chronic pancreatitis. Perhaps a few case discussions could illustrate your approach to these problems:

Case 1 - A 28-year-old woman has a 10-year history of Crohn's disease affecting the colon and small intestine. The disease is well documented with colonic biopsies showing typical granulomatous colitis. She has been put on steroids, methotrexate and infliximab, with only partial improvement in pain symptoms. She has had an ileocecal resection and contin-

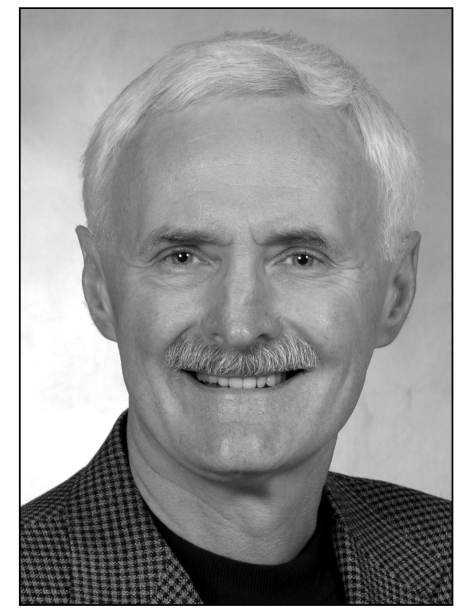

Dr Roman Jovey is currently the Program Director at CPM Health Centres Inc (Mississauga, Ontario), a group of outpatient chronic pain management clinics, as well as the Physician Director of the Credit Valley Hospital's Addictions and Concurrent Disorders Centre (Mississauga, Ontario). He is the current President of the Canadian Pain Society or side effects. One would have to assess her use of immediaterelease/short-acting (IR/SA) oxycodone to decide if she would be better managed with a controlled-release/long-acting (CR/LA) opioid analgesic. Methadone can be a useful analgesic in such patients but requires a special prescribing authorization from Health Canada.

PA: The gastroenterologist is often looking to reassess the activity of Crohn's disease by endoscopy, imaging and blood tests. It is often noted that the degree of pain seems out of proportion to the degree of disease activity. It is acknowledged that our tools may not be optimal, but this often leads to confrontation with or abandonment of the patient.

RJ: The longer a patient suffers from any persistent pain problem, the more likely it is that he or she will develop central sensitization in the dorsal horn of the spinal cord and higher brain centres. This means that the severity of pain experienced is no longer directly related to the degree of peripheral stimulation of nociceptors by inflammation or other stimuli. Sensitized nociceptors are more 'twitchy' and more easily fired by any stimulation. This results in increased pain signalling in the central nervous system. However, pain does not always equate to suffering. Individual psychosocial factors such as mood changes, the meaning of the pain and the impact on ability to function influence the degree of suffering.

PA: The gastroenterologist may fear that excess prescriptions of narcotics may lead to monitoring by the government, accusations of creating addiction by the patient, and legal problems associated with driving and work injuries.

RJ: Part of a good medical practice is good documentation. This requires an appropriately documented history, physical examination, investigations, a diagnosis and differential diagnosis, a treatment plan and ongoing monitoring of any chronic condition. In the case of prescribing long-term opioids, physicians need to document an addiction screen monitor (Opioid Risk Tool) for any aberrant drug use behaviours and adjust treatment accordingly. The use of a written prescription agreement reduces the risk of being accused of iatrogenic addiction. The use of periodic, random urine drug testing for illicit substances may help in the early diagnosis of an evolving addiction problem. Increasing requests for IR/SA opioids to treat a chronic pain problem indicates that the patient should such as an incomplete bowel obstruction. She may benefit from a trial of a tricyclic antidepressant, titrated to analgesic effects

\footnotetext{
${ }^{1}$ The Credit Valley Hospital, Mississauga; ${ }^{2}$ London Health Sciences Centre, London, Ontario

Correspondence: Dr Roman Jovey, CPM Health Clinics Inc, 404 - 6711 Mississauga Road, Mississauga, Ontario L5N 2W3.

Telephone 905-858-1368,fax 905-855-7304,e-mail drjovey@sympatico.ca
} 
be reassessed and may mean that the treatment plan needs adjustment. There is abundant medical literature available to support the view that carefully titrated, stable-dose, CR/LA opioid treatment does not cause clinically significant cognitive impairment and it certainly should not interfere with a patient's driving ability. On the other hand, frequent use of IR/SA opioids or concurrent use of sedating medications such as benzodiazepines can increase the risk.

PA: Case 2 - A 55-year-old man has a history of chronic pancreatitis related to alcohol abuse. He has had documentation of the problem, with calcification of the pancreas on computed tomography scanning. He has apparently stopped using alcohol but liberally uses narcotics and sedatives. He is requesting increasing doses of narcotics, and claims that his specialists and family physician do not want to help him anymore.

RJ: Patients with chronic pancreatitis are a treatment challenge because they will often have recurrent episodes of severe acute on chronic visceral pain. It is essential that this man's abstinence from alcohol be verified via history, collateral information and laboratory work. He should be assessed at an addiction treatment program, if he has not already been previously assessed. Sedatives are a high-risk medication in anyone with a history of alcohol abuse or dependence due to the risk of cross-addiction. He should be assessed for a concurrent mood disorder, and, if indicated, appropriate treatment should be instituted. The pattern of his pain needs to be established. With chronic, ongoing pain, his treatment plan will likely include a baseline dose of a CR/LA opioid analgesic titrated to effect along with a supply of IR/SA opioids to use with exacerbations of his disease. His treatment plan also needs to include advice on when he should go to the emergency room.

PA: Perhaps the most difficult patients have chronic abdominal pain with no anatomical diagnosis and increasing needs for narcotics. How does this change your approach?

RJ: These patients are typically labelled with some variation of functional abdominal pain syndrome. Patients with chronic abdominal pain and no specific diagnosis require more detailed assessment to rule out treatable causes of abdominal pain. There are a number of 'sleeper' diagnoses, such as celiac disease, Whipple's disease, abdominal wall pain and others, that are missed unless specifically considered. Part of this assessment should include a detailed psychosocial evaluation. Recent research on the pathophysiology of functional abdominal pain syndrome is discovering dysfunctional central nervous system pain mechanisms that involve either hypervigilance to pain signals, or a failure of central pain modulation or inhibition mechanisms. These are amenable to cognitivebehavioural treatment techniques. The only pharmacological treatment with some evidence is the use of titrated tricyclics. Long-term opioids should only be considered when patients have failed to respond to all other treatments.

I would like to make a closing comment to gastroenterologists to keep an open mind in evaluating a patient on longterm opioids who has persistent abdominal complaints. All too often, the problem is chalked up to 'narcotic gut' without thinking of other possibilities.

Dr Jovey can provide a copy of the Opioid Risk Tool and a Opioid Prescribing Agreement; he can be contacted through e-mail. 


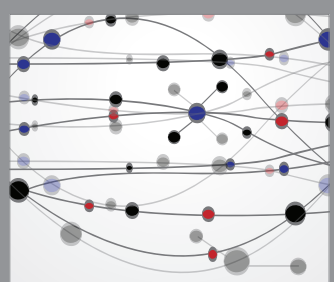

The Scientific World Journal
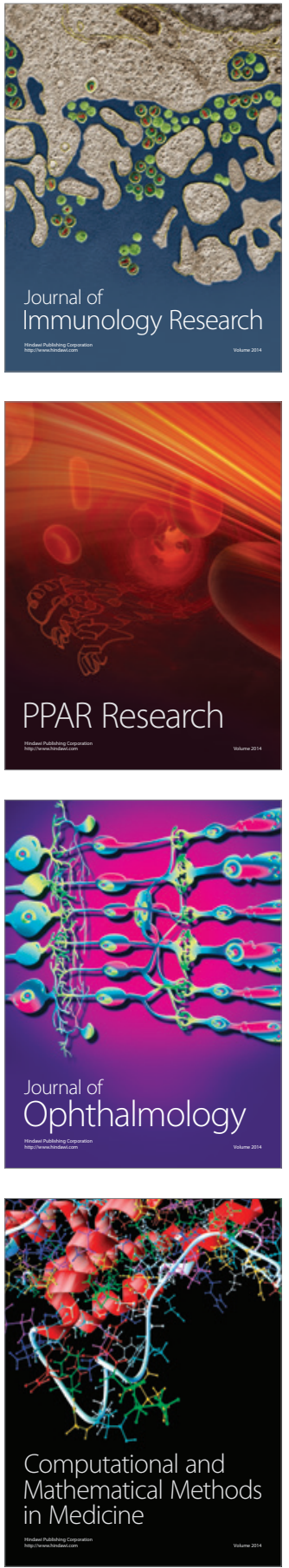

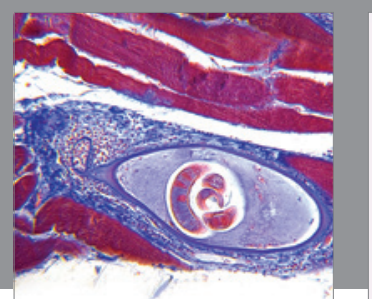

Gastroenterology Research and Practice

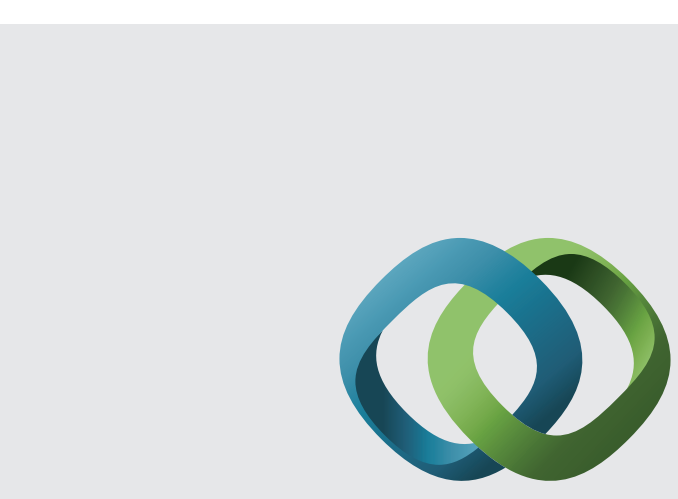

\section{Hindawi}

Submit your manuscripts at

http://www.hindawi.com
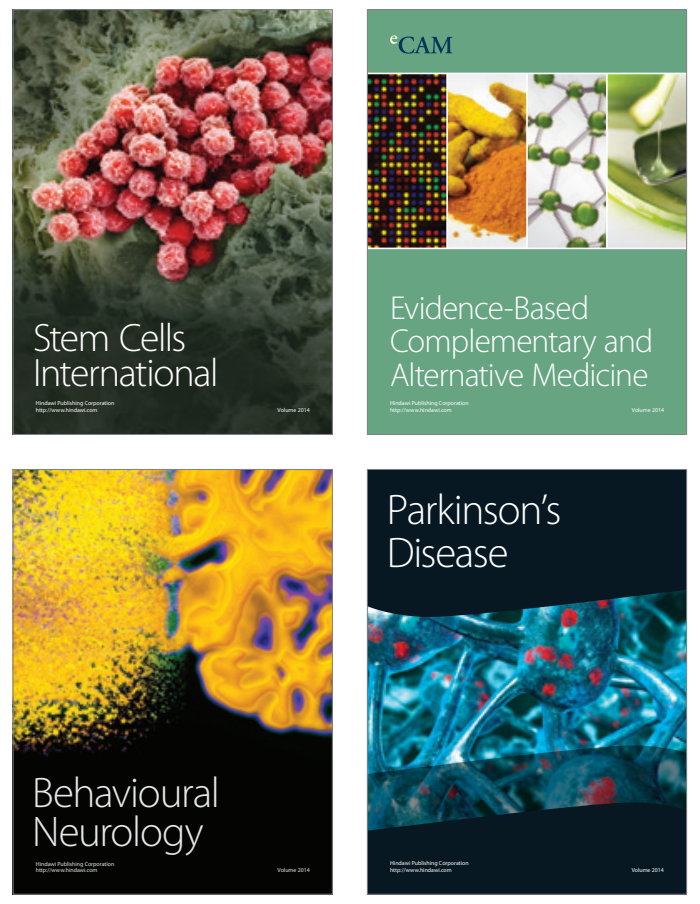
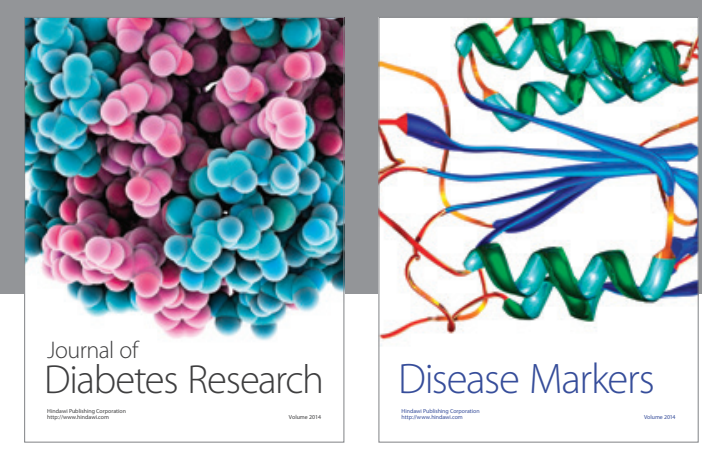

Disease Markers
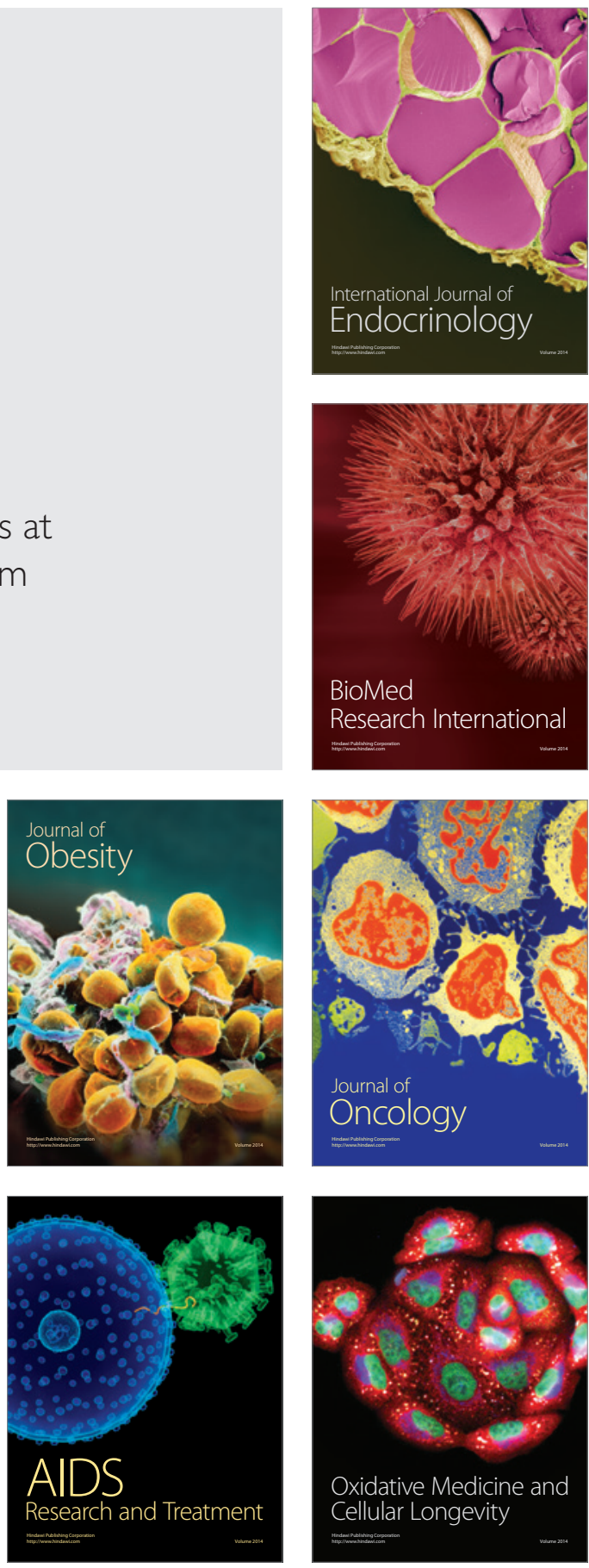